\title{
Study of the epidemiology of COVID-19 in Ontario elementary and secondary school education workers: an interim analysis following the first school year
}

\author{
Brenda L. Coleman ${ }^{1,2}$ (D) Kailey Fischer ${ }^{1} \cdot$ Robert Maunder $^{1,2} \cdot$ John Kim $^{3} \cdot$ Sharon Straus $^{2,4} \cdot$ Susan Bondy ${ }^{2} \cdot$ \\ Allison McGeer ${ }^{1,2}$
}

Received: 20 September 2021 / Accepted: 24 January 2022 / Published online: 17 February 2022

(C) The Author(s) under exclusive license to The Canadian Public Health Association 2022

\begin{abstract}
Objective To estimate the incidence of SARS-CoV-2 in education workers and the factors associated with infection between March 2020 and July 2021.

Methods A prospective cohort study of education workers working $\geq 8 \mathrm{~h}$ per week in Ontario, Canada. Participants self-reported results of tests for SARS-CoV-2 and completed online surveys about demographic information, exposures, and vaccinations against SARS-CoV-2. Participants submitted self-collected dried blood spots. Antibodies to SARS-CoV-2 spike, the receptor binding domain of spike, and nucleocapsid were assessed. Multivariable regression was used to assess risk factors for infection. Results Of 2834 participants, $85 \%$ were female, $81 \%$ were teaching staff, and $86 \%$ had received at least one dose of SARS-CoV2 vaccine. Of the 1983 who had been tested via a respiratory specimen, $4.9 \%$ reported a positive test. Five additional participants had serologic testing suggestive of a previous infection (3.6\% overall incidence). In multivariable regression analysis, risk factors for infection included exposure to a SARS-CoV-2 infected adult (adjusted incidence rate ratio (aIRR) 13.6; 95\% confidence interval 8.6, 21.3) or child (aIRR 2.3; 1.3, 4.2) in the household, or school student (aIRR 1.9; 1.2, 3.2), or travel outside the province within 14 days of testing (aIRR $6.0 ; 1.5,23.6$ ).

Conclusion In the first 18 months of the pandemic, education workers had a similar risk of infection with SARS-CoV-2 as other Ontario residents. Practicing protective measures whenever any household member has been exposed to a possible case and at all times when exposed to anyone from outside the home would help reduce the risk of infection.
\end{abstract}

\section{Résumé}

Objectif Estimer l'incidence du SRAS-CoV-2 chez les travailleuses et les travailleurs en éducation et les facteurs associés à l'infection entre mars 2020 et juillet 2021.

Méthode Étude prospective de cohortes auprès de travailleuses et de travailleurs en éducation travaillant $\geq 8$ heures par semaine en Ontario, au Canada. Les participants ont autodéclaré les résultats de tests de dépistage du SRAS-CoV-2 et répondu à des questionnaires en ligne portant sur leurs données démographiques, leurs expositions au SRAS-CoV-2 et leurs vaccins contre le virus. Les participants ont soumis des gouttes de sang séché autoprélevées. Les anticorps à la protéine $\mathrm{S}$ du SRAS-CoV-2, le domaine de liaison aux récepteurs de la protéine $\mathrm{S}$ et la nucléocapside ont été évalués. Une régression multivariée a servi à évaluer les facteurs de risque d'infection.

Résultats Sur les 2834 participants, $85 \%$ étaient des femmes, $81 \%$ étaient des enseignants et $86 \%$ avaient reçu au moins une dose de vaccin contre le SRAS-CoV-2. Sur les 1983 personnes ayant été testées au moyen d'un prélèvement respiratoire, 4,9\%

Brenda L. Coleman

Brenda.Coleman@SinaiHealth.ca

1 Sinai Health System, Toronto, ON, Canada

2 University of Toronto, Toronto, ON, Canada

3 National Microbiology Laboratory, Winnipeg, MB, Canada

4 Unity Health, Toronto, ON, Canada 
ont déclaré un test positif. Chez cinq autres participants, un test sérologique a indiqué une infection antérieure (incidence globale de 3,6\%). Selon l'analyse de régression multivariée, les facteurs de risque d'infection étaient l'exposition à un adulte infecté par le SRAS-CoV-2 (rapport de taux d'incidence ajusté [RTIa] 13,6; intervalle de confiance de $95 \%$ 8,6,21,3) ou à un enfant infecté (RTIa 2,3; 1,3,4,2) au sein du ménage, l'exposition à un élève infecté (RTIa 1,9;1,2,3,2) ou un déplacement hors province dans les 14 jours ayant précédé le test (RTIa 6,0; 1,5, 23,6).

Conclusion Au cours des 18 premiers mois de la pandémie, le risque d'infection par le SRAS-CoV-2 chez les travailleuses et les travailleurs en éducation était semblable au risque des autres résidents de l'Ontario. L'application de mesures de protection chaque fois qu'un membre du ménage a été exposé à un cas possible, et en tout temps lorsqu'on est exposé à une personne de l'extérieur du ménage, contribuerait à réduire le risque d'infection.

Keywords COVID-19 $\cdot$ Education $\cdot$ Cohort $\cdot$ Risk factors

Mots-clés COVID-19 · éducation $\cdot$ cohorte $\cdot$ facteurs de risque

\section{Introduction}

Teachers and other education workers may be at increased risk of coronavirus disease (COVID-19) due to their close and prolonged contact with students, co-workers, parents, and volunteers. Like other adults, they are also exposed to their own household members, extended family and friends, and other members of the public.

The contribution of schools to overall transmission of SARS-CoV-2 and the occupational risk to education workers remains uncertain. Certainly, the highest risk of transmission is to family members in the same household (Liu et al., 2020; Madewell et al., 2020). Several prospective studies done in educational settings have reported that staff-to-staff transmission risk is significantly higher than staff-to-child or child-to-staff (Bi et al., 2021; Gandini et al., 2021; Macartney et al., 2020; Meuris et al., 2021; Varma et al., 2021).

The objective of this interim analysis was to estimate the cumulative incidence of COVID-19 in Ontario's teachers and education workers during the first 18 months of the pandemic, and to identify workplace-, community-, and individual-level risk and protective factors for COVID19 in this population.

\section{Background and context}

Ontario is the largest province in Canada, with 14.7 million citizens. Its 3967 elementary and 877 secondary public schools and 1250 private schools serve over 2 million students and employ over 160,000 full-time equivalent staff (Ontario Ministry of Education, 2021; York Region tutoring, 2018). Concerns about the spread of COVID-19 triggered the closure of all schools on March 12, 2020, with remote learning instituted until June 30, 2020. Schools were re-opened to fully remote, fully face-to-face, and hybrid (combined online and in-person classes) learning on September 8, 2020, with staggered opening dates. Schools in high COVID-19 activity regions were closed again on January 8, 2021, but all were reopened by February $16^{\text {th }}$. Elementary and secondary schools were closed to in-person learning again on April $12^{\text {th }}$ and did not re-open for the remainder of the 2020-2021 school year (Gallagher-Mackay et al., 2021; Government of Ontario, 2020a).

During closures, all students were able to participate in remote/online learning. During open periods, remote learning was available for those who chose it. Staff and students in grades 4 to 12 were required to wear masks indoors, on school property, on school vehicles, and outdoors when a $2 \mathrm{~m}$ distance could not be maintained at the beginning of the 2020/2021 school year (Government of Ontario, 2020b). This was expanded to grades 1-12 in January 2021 (Government of Ontario, 2021). Kindergarten students were not required to but were encouraged to wear masks in indoor spaces while special accommodations were made for students with special education needs. Staff and students were asked to stay home and self-isolate if they failed daily screening for symptoms compatible with COVID-19. Of note, individual school boards could institute requirements beyond those mandated by the provincial government.

A limited supply of vaccine against COVID-19 became available in Ontario on December 14, 2020, with increasing supply over the first 6 months of 2021. A phased rollout of vaccines followed, with some education workers eligible as early as April, but most eligible starting in May 2021 (Ontario Ministry of Health, 2021). Youth aged 12 years or older become eligible for vaccination starting May 23, 2021. Most Ontario adults were vaccinated with the Pfizer-BioNTech or Moderna mRNA vaccines, with a smaller percentage receiving the viral vector vaccine produced by AstraZeneca. The PfizerBioNTech vaccine was the only vaccine approved for use in youth aged 12-17 years in Canada until late August 2021. 


\section{Methods}

The COVID-19 Cohort Study of teachers and education workers is a prospective cohort study that started enrolling participants on February 18, 2021. The study is open to all education workers (teachers, educational assistants, school office staff, custodians, librarians, early childhood educators, etc.) aged 18-74 years, employed in any capacity in an Ontario school or school board, working an average of $\geq 8 \mathrm{~h} /$ week (remote or in person) during the 2020-2021 school year, and planning to continue working for at least 3 months after enrolment. To permit dried blood spot (DBS) self-collection, eligibility was restricted to those who did not have a bleeding disorder, had not received chemotherapy in the previous 4 weeks, and had not had a bilateral mastectomy. Study correspondence was available in English and French. The study was approved by the research ethics board of Mount Sinai Hospital and conducted in compliance with the Tri-Council Policy Statement 2 (Government of Canada, 2018) and good clinical practice guidelines (Government of Canada, 2019). This report is an interim analysis with data available to July 17, 2021.

Key partners (education workers' associations, federations, unions) advertised the study to their membership using a variety of media, including direct emails and/or notices in newsletters/member updates, social media, and postings on their websites. Facebook and Twitter messages were shared by the investigators and their peers. Participants were also asked to share study information with their colleagues. The advertisements took potential participants to the study's webpage (www.tibdn.ca/covid-19/education) that linked them to the electronic information and consent form. After consent, participants completed an online baseline survey asking about personal, household, and work-related information and a survey asking about dates and manufacturer of COVID-19 vaccines received. Emails were sent every second week linking participants to a survey assessing exposures and reminding them to complete surveys about COVID-19 tests completed/respiratory illnesses experienced and to update the vaccination survey as needed. DBS kits were mailed to all participants who consented and completed the baseline survey.

DBS samples were collected at enrollment, $\leq 48 \mathrm{~h}$ before receipt of a COVID-19 vaccine, 30 days following each dose of a vaccine, and every 13 weeks after the last sample. To encourage timely collection of the first DBS samples, participants were offered a \$20 electronic gift card upon its receipt at the study site and results (positive/negative for antibodies) were shared with them. Since participants were enrolled after vaccines were available to some, not all participants provided all samples (e.g., before their first vaccination). DBS samples were obtained by self-collection of capillary blood with a lancet onto
Whatman $903 \circledR$ protein saver cards which were permitted to air dry then placed in gas-impermeable bags with desiccant and mailed to the study site. Samples were then stored at $4^{\circ} \mathrm{C}$ until they were sent to the laboratory where they were stored at $-80^{\circ} \mathrm{C}$ until processed for testing.

Samples were tested at the National Microbiology Laboratory (Winnipeg, MB) to determine the presence of IgG antibodies to spike (S1), receptor binding domain (RBD) of the spike, and nucleocapsid (NP) SARS-CoV-2 proteins. On the day samples were processed, samples were removed from the $-80^{\circ} \mathrm{C}$ freezer and thawed at room temperature for $30 \mathrm{~min}$. Using the BSD robotics semi-automated DBS puncher, a 0.25 inch punch of dried blood that was fully saturated was punched into a 96-well microtitre plate. The punch was eluted overnight at $4^{\circ} \mathrm{C}$ in $130 \mu \mathrm{l}$ of elution buffer (DPBS pH 7.4, 0.5\% BSA, $0.05 \%$ Tween 20 ) with shaking. Then, samples were shaken at room temperature for $30 \mathrm{~min}$ and the eluates were transferred to $1.5 \mathrm{ml}$ Sarstedt ${ }^{\circledR}$ tubes. Samples were tested using the Bio-Rad Bioplex 2200 SARS-CoV-2 IgG assay. The assay measures the relative concentration of SARS-CoV-2 antibodies to RBD, S1, and NP in plasma samples.

The Bio-Rad Bioplex 2200 SARS-CoV-2 calibrators and controls were re-calibrated and validated to account for the lower amount of antibody in a DBS sample. To relate the values obtained from a DBS sample to those of an equivalent plasma sample, the relative value for each target was multiplied by an experimentally determined factor. To convert the relative Bioplex values to concentrations, a dilution series of the World Health Organization first international standard for anti-SARSCoV-2 immunoglobulin (human) (NIBSC code: 20/136) was run and the equation of the line was used to calculate the concentrations of each target. For this analysis, samples were considered positive for previous infection if the NP and one of either the RBD or S1 levels were above the specified threshold concentration.

\section{Variables}

The outcome for this interim report was evidence of SARSCoV-2 infection defined as either a self-reported positive test for COVID-19 from a respiratory sample (PCR or rapid antigen) and/or a DBS sample positive for NP and RBD or S1 anti-SARS-CoV-2 antibodies.

Risk factor information was collected using the baseline, test/illness, and vaccination questionnaires. Baseline questionnaires gathered household size and composition; travel history; COVID-19 testing and exposure to people with COVID19 prior to enrolment; health and demographic information; exposure to non-household people; personal, student, and coworker protective practices; occupation and years of 
experience; school size and type (elementary, secondary, etc.); and hours worked and hours of face-to-face contact with students. The test/illness questionnaire collected date and result of test(s), contact with people confirmed and suspected of having COVID-19, travel, and group activities attended in the 14 days before testing/illness. Vaccination questionnaires gathered date(s) and manufacturer(s) of vaccines received. Vaccination was defined as having received a dose of COVID-19 vaccine $\geq 14$ days before testing. Unvaccinated days at risk were computed using the number of days between March 17, 2020 (onset of the first wave of COVID-19 in Ontario) and 14 days after receipt of their second dose of vaccine or July 17 , 2021 (date of data freeze). Neighbourhood risk groups, ranked by their cumulative incidence (to March 28, 2021) and grouped into deciles, were used to estimate neighbourhood risk (ICES, 2021). Region of residence was based on the first letter of Canada Post forward sortation areas (K, east; L, central; M, Toronto; N, southwest; P, north). Behaviour risk scores were based on a 4point Likert scale for five questions about physical distancing, mask-wearing, covering coughs, hand hygiene, and staying home when symptomatic.

Participants who were ill or tested for COVID-19 were asked to identify known exposures to people who had tested positive for SARS-CoV-2 within 14 days of the date of testing. Given that it was possible to be exposed to more than one person who carried the virus, data were collected separately for household child or adult, coworker, student, friend/extended family member, or other contact. For variables other than exposure to a person with COVID-19, missing data were either logically imputed using other data points or imputed using the hot deck method (Andridge \& Little, 2010). A sensitivity analysis was conducted to assess the impact of imputation.

\section{Statistical analyses}

The crude cumulative incidence was estimated using the total number of participants with at least one positive respiratory and/or serology test. Risk factors for infection were assessed using a log-linear model (Poisson) with robust variance estimators. Multivariable logistic regression was employed to adjust for confounding and to assess the impact of other variables. Effect measure modification effects were examined on the additive and multiplicative scales. Covariates with non-linear associations were transformed or categorized. Models were assessed for goodness of fit and leverage. All analyses were conducted using Stata SE® version 16.1 (StatCorp LLC, 2021). A two-sided $p$-value of $<0.05$ was considered statistically significant.

\section{Results}

Of 2876 consenting education workers, 2834 (98.5\%) completed their baseline survey before July 17, 2021, and were included in this interim analysis. The mean age of participants was 45 years, $84.6 \%$ were female, $2295(81 \%)$ were teachers or principals with teaching responsibilities, and $59 \%$ worked in an elementary school (Table 1). As of July $17^{\text {th }}, 2446$ (86.3\%) had received at least one dose of a COVID-19 vaccine and $1617(57.1 \%)$ had received two doses.

Overall, 1986 of $2834(70 \%)$ participants had had at least one respiratory sample tested for COVID-19 since the beginning of the pandemic; 98 (3.5\%) reported a positive result. Three people were positive during the 2019/20 school year, none tested positive over the summer break, and the remaining 95 tested positive during the 2020/21 school year (see Fig. 1). Rates of infection were similar by region within the province, with $2.1 \%$ (95\% confidence interval (CI) 1.1, 3.7), 3.3\% (95\% CI 1.2, 7.2), 3.9\% (95\% CI 2.8, 5.2), $4.0 \%$ (95\% CI 2.6, 5.7), and $4.6 \%$ (95\% CI 3.1, 6.6) of participants infected in the east, north, central, Toronto, and southwest regions, respectively ( $p=0.19)$. Twenty-three of the 1252 participants for whom antibody tests were available for this interim analysis were considered positive, including 5 who reported a previous negative respiratory sample test and 2 who reported no previous test for an overall incidence of $3.6 \%$ (95\% CI 2.9, 4.3). Of the 825 participants tested using both respiratory and blood samples, 44 (5.3\%) had evidence of infection: 16 were positive by both a respiratory sample and serology, 5 were positive by serology alone, and 23 reported a positive respiratory test but had no detectable antibodies.

In crude (unadjusted) analyses, the risk factors significantly associated with having had COVID-19 include known exposure to a person with COVID-19, travel outside of the province, and having chronic obstructive pulmonary disease (see Table 1). As shown in Table 2, after adjusting for vaccination status, days at risk without two doses of vaccine, and household size, factors significantly associated with COVID-19 infection included exposure to an adult or child living in the same household who tested positive for COVID-19, exposure to a student with COVID-19, and participant or household member who travelled out of province 14-21 days before the date of the participant's positive COVID-19 test.

There were no substantive differences in the incidence rate ratios (IRR) when the analyses were restricted to the 2295 teaching staff (teachers or principals/vice principals with teaching duties) compared with the full cohort. However, when the analysis was restricted to non-teaching staff $(N=539)$, exposure to an infected adult household member (adjusted IRR 11.6; $95 \%$ CI $4.0,33.6)$ was the only variable that was a statistically significant variable after adjusting for exposures to other types of contacts, vaccine status, and number of housemates. A sensitivity analysis to assess the impact of imputing missing data 
Table 1 Demographic, household, workplace, and neighbourhood factors of Ontario education workers, by COVID-19 infection status as of July 17, 2021

\begin{tabular}{|c|c|c|c|}
\hline & $\begin{array}{l}\text { No positive test } \\
N=2729\end{array}$ & $\begin{array}{l}\text { Positive for COVID-19 } \\
N=105\end{array}$ & $\begin{array}{l}\text { Full cohort } \\
N=2834\end{array}$ \\
\hline Female & $2305(84.5)$ & $94(89.5)$ & $2399(84.6)$ \\
\hline Male & $418(15.3)$ & $11(10.5)$ & $429(15.1)$ \\
\hline Non-binary & $6(0.2)$ & $0(--)$ & $6(0.2)$ \\
\hline Age, mean (SD) & $45.1(8.9)$ & $43.8(9.0)$ & $45.0(8.9)$ \\
\hline \multicolumn{4}{|l|}{ Vaccine status $^{\text {a }}$} \\
\hline Unvaccinated & $368(13.5)$ & $20(19.0)$ & $388(13.7)$ \\
\hline One dose & $794(29.1)$ & $35(33.3)$ & $829(29.2)$ \\
\hline Two doses & $1567(57.4)$ & $50(47.6)$ & $1617(57.1)$ \\
\hline Unvaccinated days at risk, median (IQR) & $468(457-487)$ & $477(458-487)$ & $468(457-487)^{*}$ \\
\hline \multicolumn{4}{|l|}{ Household size } \\
\hline 1 or 2 & $743(27.2)$ & $26(24.8)$ & $769(27.1)$ \\
\hline 3 & $490(18.0)$ & $19(18.1)$ & $509(18.0)$ \\
\hline 4 & $869(31.8)$ & $39(37.1)$ & $908(32.0)$ \\
\hline 5 or more & $627(23.0)$ & $21(20.0)$ & $648(22.9)$ \\
\hline Exposed to child case in household ${ }^{\mathrm{b}}$ & $18(0.7)$ & $15(14.3)$ & $33(1.2)^{* *}$ \\
\hline Exposed to adult case in household ${ }^{\mathrm{b}}$ & $37(1.4)$ & $33(31.4)$ & $70(2.5)^{* *}$ \\
\hline Exposed to co-worker case ${ }^{\mathrm{b}}$ & $220(9.7)$ & $16(15.2)$ & $236(8.3)^{*}$ \\
\hline Exposed to student case, school $^{\mathrm{b}}$ & $266(9.7)$ & $25(23.8)$ & $291(10.3)^{* *}$ \\
\hline Exposed to family friend case ${ }^{\mathrm{b}}$ & $173(6.3)$ & $16(15.2)$ & $189(6.7)^{* *}$ \\
\hline Exposed to "other" case ${ }^{\mathrm{b}}$ & $44(1.6)$ & $6(5.7)$ & $50(1.8)^{* *}$ \\
\hline \multicolumn{4}{|l|}{ Neighbourhood risk $^{\mathrm{c}}$} \\
\hline $1-2$ & $250(9.2)$ & $18(17.1)$ & $268(9.5)^{*}$ \\
\hline $3-4$ & $543(19.9)$ & $20(19.0)$ & $563(19.9)$ \\
\hline $5-6$ & $641(23.5)$ & $27(25.7)$ & $668(23.6)$ \\
\hline $7-8$ & 707 (25.9) & $25(23.8)$ & $732(25.8)$ \\
\hline 9-10 (lowest incidence) & $588(21.5)$ & $15(14.3)$ & $603(21.3)$ \\
\hline \multicolumn{4}{|l|}{ Region (based on forward sortation area) } \\
\hline East $(\mathrm{K})$ & $506(18.5)$ & $11(10.5)$ & $517(18.2)$ \\
\hline Central (L) & 919 (33.7) & $37(35.2)$ & $956(33.7)$ \\
\hline Toronto (M) & $555(20.3)$ & $27(25.7)$ & $582(20.5)$ \\
\hline Southwest (N) & $604(22.1)$ & $25(23.8)$ & $629(22.2)$ \\
\hline North $(\mathrm{P})$ & $145(5.3)$ & $5(4.8)$ & $150(5.3)$ \\
\hline \multicolumn{4}{|l|}{ Race/ethnicity } \\
\hline Caucasian/white & $2450(89.8)$ & $91(86.7)$ & $2541(89.7)$ \\
\hline Other (including mixed heritage) & $279(10.2)$ & $14(13.3)$ & $293(10.3)$ \\
\hline Travel prior to illness ${ }^{\mathrm{d}}$ & $8(0.3)$ & $2(1.9)$ & $10(0.4)^{*}$ \\
\hline \multicolumn{4}{|l|}{ Health status } \\
\hline Excellent & $616(22.6)$ & $26(24.8)$ & $642(22.6)$ \\
\hline Very good & $1280(46.9)$ & $48(45.7)$ & $1328(46.9)$ \\
\hline Good & $700(25.6)$ & $30(28.6)$ & $730(25.8)$ \\
\hline Fair/poor & $133(4.9)$ & $1(1.0)$ & $134(4.7)$ \\
\hline Chronic obstructive pulmonary disease & $17(0.6)$ & $3(2.9)$ & $20(0.7)^{*}$ \\
\hline Diabetes mellitus & $101(3.7)$ & $2(1.9)$ & $103(3.6)$ \\
\hline Neurological disorder & $45(1.6)$ & $3(2.9)$ & $48(1.7)$ \\
\hline Tobacco use (current) & $117(4.3)$ & $8(7.6)$ & $125(4.4)$ \\
\hline \multicolumn{4}{|l|}{ Workplace } \\
\hline Elementary school & $1606(58.9)$ & $68(64.8)$ & $1674(59.1)$ \\
\hline
\end{tabular}


Table 1 (continued)

\begin{tabular}{|c|c|c|c|}
\hline & $\begin{array}{l}\text { No positive test } \\
N=2729\end{array}$ & $\begin{array}{l}\text { Positive for COVID-19 } \\
N=105\end{array}$ & $\begin{array}{l}\text { Full cohort } \\
N=2834\end{array}$ \\
\hline Secondary school & $874(32.1)$ & $27(25.7)$ & $901(31.8)$ \\
\hline Mixed, elementary, and secondary & $229(8.4)$ & $9(8.6)$ & $238(8.4)$ \\
\hline Board office & $17(0.6)$ & $1(0.9)$ & $18(0.6)$ \\
\hline \multicolumn{4}{|l|}{ Occupation } \\
\hline Teacher/instructor & $2211(81.0)$ & $84(80.0)$ & $2295(81.0)$ \\
\hline Educational assistant/ECE & $222(8.1)$ & $13(12.4)$ & $235(8.3)$ \\
\hline Administrative & $181(6.6)$ & $5(4.8)$ & $186(6.6)$ \\
\hline Professional & $115(4.2)$ & $3(2.9)$ & $118(4.2)$ \\
\hline \multicolumn{4}{|l|}{ Student contact, hours per week } \\
\hline None & $203(7.4)$ & $8(7.6)$ & $211(7.4)$ \\
\hline $1-31$ & $1736(63.6)$ & $56(53.3)$ & $1792(63.2)$ \\
\hline$\geq 32$ & $790(29.0)$ & $41(39.1)$ & $831(29.3)$ \\
\hline \multicolumn{4}{|l|}{ Student contact, number per week } \\
\hline None & $206(7.5)$ & $8(7.6)$ & $214(7.5)$ \\
\hline $1-24$ & $1458(53.4)$ & $57(54.3)$ & $1515(53.5)$ \\
\hline$\geq 25$ & $1065(39.0)$ & $40(38.1)$ & $1105(39.0)$ \\
\hline \multicolumn{4}{|l|}{ Student contact, level } \\
\hline None & $206(7.5)$ & $8(7.6)$ & $214(7.5)$ \\
\hline Same room, rarely $<2 \mathrm{~m}$ & $503(18.4)$ & $13(12.4)$ & $516(18.2)$ \\
\hline Same room, often $<2 \mathrm{~m}$ & $1405(51.5)$ & $50(47.6)$ & $1455(51.3)$ \\
\hline Same room, physical contact & $615(22.5)$ & $34(32.4)$ & $649(22.9)$ \\
\hline \multicolumn{4}{|l|}{ Co-worker contact, level } \\
\hline None & $388(14.2)$ & $17(16.2)$ & $405(14.3)$ \\
\hline Same room, rarely $<2 \mathrm{~m}$ & $1233(45.2)$ & $39(37.1)$ & $1272(44.9)$ \\
\hline Same room, often $<2 \mathrm{~m}$ & $1020(37.4)$ & $47(44.8)$ & $1067(37.6)$ \\
\hline Same room, physical contact & $88(3.2)$ & $2(1.9)$ & $90(3.2)$ \\
\hline Students' risk scores $\leq 5^{\mathrm{e}}$ & $1218(44.6)$ & $38(36.2)$ & $1256(44.3)$ \\
\hline $6-20$ & $1511(55.4)$ & $67(63.8)$ & $1578(55.7)$ \\
\hline Participants' risk score $\leq 5^{\mathrm{e}}$ & $2675(98.0)$ & $105(100)$ & $2780(98.1)$ \\
\hline $6-20$ & $54(2.0)$ & $0--$ & $54(1.9)$ \\
\hline Co-workers' risk score $\leq 5^{\mathrm{e}}$ & $2519(92.3)$ & $97(92.4)$ & $2616(92.3)$ \\
\hline $6-20$ & $210(7.7)$ & $8(7.6)$ & $218(7.7)$ \\
\hline
\end{tabular}

$* * p \leq 0.001$

$* p \leq 0.05$

${ }^{a}$ Vaccinated $\geq 14$ days before tested (or baseline if not tested)

${ }^{\mathrm{b}}$ Within 14 days of illness; exposure to more than one case was possible

${ }^{\mathrm{c}}$ Ranked neighbourhood risk (using cumulative incidence of COVID-19) by forward sortation area (ICES, 2021)

${ }^{\mathrm{d}}$ Travel out of province within 14 (by participant) or 21 days (by household member) of test

${ }^{\mathrm{e}}$ Score: 0-5 (always or usually) vs 6-20 (occasionally, rarely, or never) practice protective behaviour

detected no substantive differences in estimates compared with the full cohort analyses (data not shown).

Of the 2834 participants, 677 (23.9\%) reported being exposed to someone who had COVID-19. Of those 677 participants, $68(10.0 \%)$ had a positive respiratory specimen test, 2 $(0.4 \%)$ tested positive by blood sample only, $11(16.2 \%)$ by both, and 57 (12.7\%) were not tested by either method.
Table 3 depicts the probability of COVID-19 infection by the relationship with the person(s) to whom they were exposed. As expected, people exposed to more than one person with COVID-19 within the previous 14 days had a higher probability of infection (e.g., child and adult in household) than those exposed to only one person. Although the secondary attack rate was significantly higher $(p<0.001)$ when 


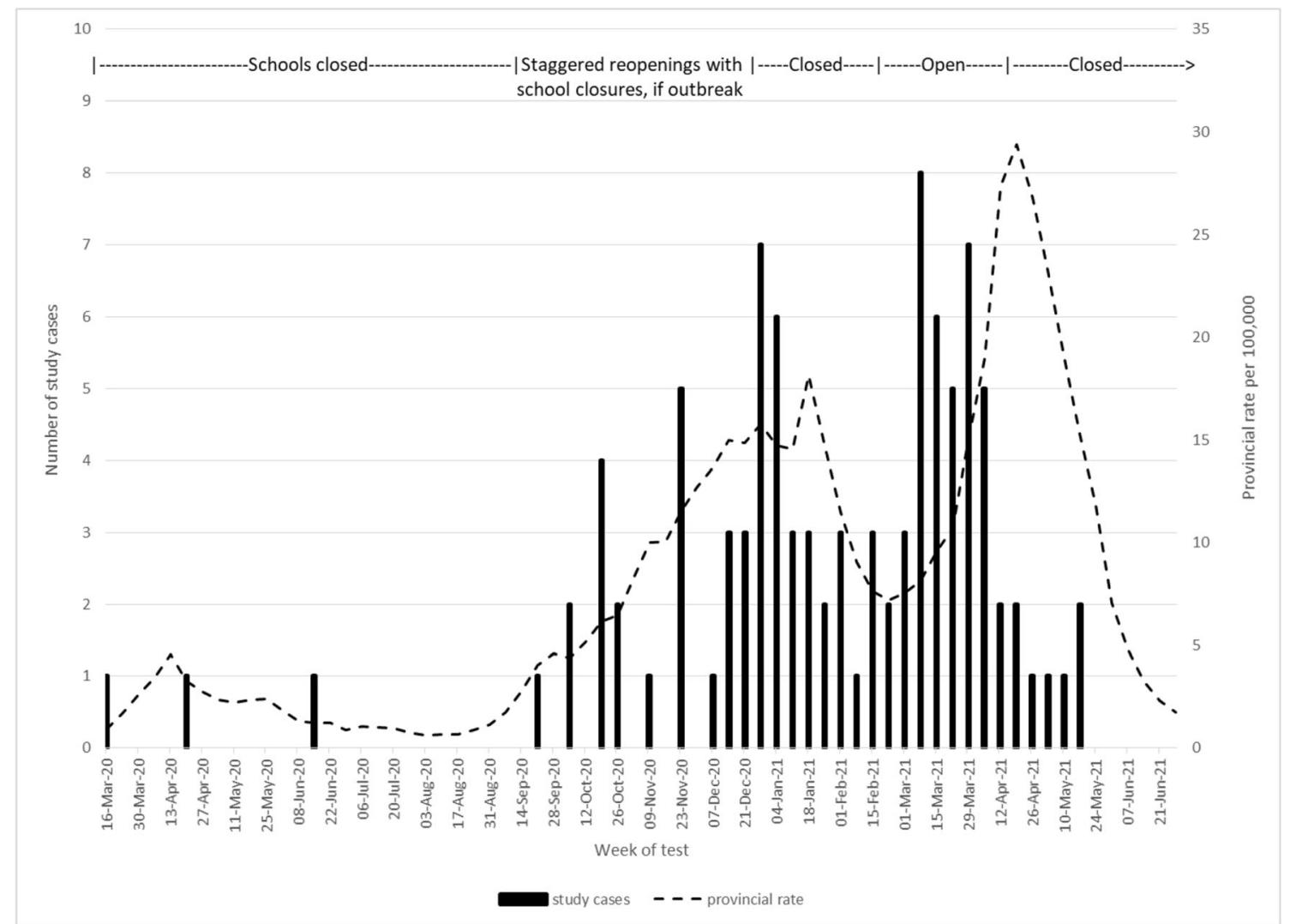

Fig. 1 Number of reported cases of SARS-CoV-2 from study participants and provincially, 2020-2021. Source of provincial case data: https://data. ontario.ca/dataset/status-of-covid-19-cases-in-ontario-by-public-health-unit-phu

Table 2 Variables associated with COVID-19 infection, Ontario education workers to July 2021

\begin{tabular}{|c|c|c|c|c|}
\hline Variable & $\begin{array}{l}\text { Crude IRR } \\
(95 \% \mathrm{CI})\end{array}$ & $p$-value & $\begin{array}{l}\text { Adjusted }{ }^{\mathrm{a}} \text { IRR } \\
(95 \% \mathrm{CI})\end{array}$ & $p$-value \\
\hline Not exposed to known case & Referent & $<0.001$ & Referent & $<0.001$ \\
\hline Exposed to adult case in home ${ }^{b}$ & $18.1(12.9,25.3)$ & & $13.6(8.6,21.3)$ & \\
\hline Not exposed to known case & Referent & $<0.001$ & Referent & 0.006 \\
\hline Exposed to child case in home ${ }^{b}$ & $14.1(9.2,21.6)$ & & $2.3(1.3,4.2)$ & \\
\hline Not exposed to known case & Referent & $<0.001$ & Referent & 0.010 \\
\hline Exposed to student case ${ }^{\mathrm{b}}$ & $2.7(1.8,4.2)$ & & $1.9(1.2,3.2)$ & \\
\hline Not exposed to known case & Referent & $<0.001$ & Referent & 0.06 \\
\hline Exposed to friend case ${ }^{\mathrm{b}}$ & $2.5(1.5,4.2)$ & & $1.7(0.9,2.9)$ & \\
\hline Not exposed to known case & Referent & 0.002 & Referent & 0.08 \\
\hline Exposed to other contact case $\mathrm{b}^{\mathrm{b}, \mathrm{c}}$ & $3.4(1.5,7.3)$ & & $1.8(0.9,3.7)$ & \\
\hline Not exposed to known case & Referent & 0.009 & Referent & 0.11 \\
\hline Exposed to co-worker case ${ }^{\mathrm{b}}$ & $2.0(1.2,3.3)$ & & $1.5(0.9,2.5)$ & \\
\hline No out-of-province travel & Referent & 0.008 & Referent & 0.010 \\
\hline Out-of-province travel ${ }^{\mathrm{d}}$ & $5.5(1.6,19.2)$ & & $6.0(1.5,23.6)$ & \\
\hline
\end{tabular}

$i R R$ incidence rate ratio

${ }^{\text {a }}$ Adjusted for vaccination status ( $\geq 14$ days before illness onset/test date), unvaccinated days at risk, household size, and other variables in table

${ }^{\mathrm{b}}$ Within 14 days of illness onset/test date; participants may have been exposed to $>1$ known case

${ }^{\mathrm{c}}$ Not household, school/work, nor friend

${ }^{\mathrm{d}}$ Out-of-province travel within 14 days (by participant) or 21 days (by household member) of illness onset/test date 
Table 3 Percent positive after known exposure to a person with COVID-19, Ontario education workers to July 2021

\begin{tabular}{|c|c|c|c|}
\hline Case description & $\begin{array}{l}\text { Number exposed } \\
\text { to a case }\end{array}$ & $\begin{array}{l}\text { Number infected } \\
\text { after exposure }\end{array}$ & $\begin{array}{l}\text { Percent exposed who } \\
\text { were infected }\end{array}$ \\
\hline Child in household & 14 & 2 & 14.3 \\
\hline Adult in household & 34 & 9 & 26.5 \\
\hline Child and adult in household & 9 & 6 & 66.7 \\
\hline Household and any other ${ }^{\mathrm{a}}$ & 32 & 19 & 59.4 \\
\hline Extended family or friend & 128 & 9 & 7.0 \\
\hline Co-worker & 131 & 5 & 3.8 \\
\hline Student & 190 & 13 & 6.8 \\
\hline Co-worker and student & 50 & 2 & 4.0 \\
\hline Work and any other & 62 & 4 & 6.4 \\
\hline Other (not included above) & 27 & 1 & 3.7 \\
\hline
\end{tabular}

${ }^{\text {a }}$ Not household member, work-related, nor friend exposed to a case within the same household ( $17 / 57$ or $29.8 \%$ ) than to a case at work (20/371 or 5.4\%), the number of cases was higher for those exposed at work.

\section{Discussion}

In this cohort of people working for the elementary or secondary school systems in Ontario, the cumulative incidence of infection with SARS-CoV-2 was 3.6\% (95\% CI 2.9, 4.3). This is similar to the $3.7 \%$ cumulative rate for Ontario residents of all ages who tested positive to July 17, 2021 (Public Health Ontario, 2021) and the 4\% seroprevalence reported for Canadians 17-60 years of age who donated blood in May 2021 (Canadian Blood Services, 2021). These results are not unexpected given the shift to remote learning and working from home during peak periods of the pandemic.

Our results indicate that the risk of SARS-CoV-2 transmission was significantly higher between people living in the same household (IRR 2.6 and 12.4) than between people in work (IRR 1.5 and 1.9) or other social (IRR 1.7 and 1.9) situations. These results concur with findings of a contact-tracing study conducted in the United States from January through March 2020 in which $24.5 \%$ of known exposures were attributed to a household member and $8.5 \%$ within the workplace while $15 \%$ were considered travel-related (Ortiz et al., 2021). Similar results were reported in a contact-tracing study conducted in China in which the secondary infection rate was 9-14\% when the case was from the same household, 3-8\% when it was a work colleague, and 3-5\% when it was another social contact (Ng et al., 2021). These researchers determined that sharing a bedroom and speaking directly with the case for $30 \mathrm{~min}$ or longer were significantly associated with household transmission. Being in contact with more than one case, car-pooling, and speaking directly with cases for $30 \mathrm{~min}$ or longer were associated with transmission in work and social situations. Similarly, a study of Chinese households showed secondary attack rates of $27.8 \%$ for spouses of cases, $17 \%$ for nonspousal adults, and $4 \%$ for children (Li et al., 2020). It is noteworthy that in our study, although the rate of transmission was higher within households, the fact that work exposures were more than six times as common as household exposures (despite remote learning during periods of high positivity) means that similar numbers of infections occurred in participants exposed to an infected student or co-worker $(N=20)$ as to an infected household member $(N=17)$.

Like several other studies, we found no difference in the risk of infection to education workers exposed to students of different ages. A systematic literature review found comparable rates of COVID-19 illness for children attending primary and secondary school as the adult staff at those institutions (Irfan et al., 2021). Similarly, a seroprevalence survey of elementary school students in Switzerland found that $2.8 \%$ tested positive for antibodies in June 2020, with no difference by age group (Ulyte et al., 2021).

Contrary to our findings, some studies have reported that when education workers were infected at work, exposures were more likely attributed to a co-worker than to students (Gandini et al., 2021; Varma et al., 2021). In Italy, secondary cases among non-teaching staff were all attributed to contact with an infected co-worker (i.e., none to students) (Gandini et al., 2021). In our study, sub-group analyses restricted to non-teaching staff found that exposures to infected students or co-workers were not significant predictors of infection.

In our study, $33 \%$ of positive cases reported not knowingly having been in contact with an infected person in the 14 days before their COVID-19 test. Contact-tracing studies in other countries have shown similar results, with 40 $60 \%$ of cases reporting no known contact with a case in Iceland, Germany, and the USA (Ehrhardt et al., 2020; Gudbjartsson et al., 2020; Lash et al., 2021). The high 
percentage of unknown contacts is not unexpected since transmission can occur from asymptomatic and paucisymptomatic cases (Li et al., 2021; $\mathrm{Ng}$ et al., 2021).

Twenty percent of the participants in our study who travelled out of province within the 14 days prior to their COVID-19 test, or whose household members travelled within 21 days of their test, tested positive. Other studies have reported travel as a risk factor as well. The secondary attack rate among train passengers in one study was $0.3 \%$ and increased by $0.15 \%$ per hour of travel with an infected person, but was as high as $3.5 \%$ when seated adjacent to an infected person (Hu et al., 2021). Authors of a contract-tracing study done in early 2020 in the USA reported that $9.5 \%$ of cases were exposed due to international travel, with another $5.5 \%$ exposed while travelling within the USA (Ortiz et al., 2021). A similar study done in Iceland in March 2020 noted that early cases were largely exposed through international travel while later cases were more often exposed to infected family members (Gudbjartsson et al., 2020). In contrast to the Icelandic study, all travel-related cases in our cohort were detected during the second and third waves of the pandemic (December 2020 through July 2021).

A strength of our study is that it was open to education workers across the entire province of Ontario, including education workers in both urban and rural locations, was available in either English or French, and questionnaires were available online or on paper, making it accessible to anyone who was interested. Our participant characteristics (age, gender, type of school, and ethnicity) largely reflect the teaching population of Ontario (Ontario College of Teachers, 2020; Ontario Ministry of Education, 2019; Turner Consulting Group, 2015). There were also a number of limitations. The participants are a convenience sample representing a small proportion of all education workers. COVID-19 testing of respiratory specimens and results were self-collected and could not be validated. The relatively low proportion of cases reported by testing of respiratory specimens that were confirmed by serology was unexpected, although it is possible that relatively intensive testing in schools may have identified milder illness in education workers, resulting in a more rapid decline in antibody titres than have been found in other studies. There may also be information bias regarding exposure to people with COVID-19. Although this may be non-differential, it is more likely that participants who tested positive would recall exposure to a case than those who did not. Participants also had intimate knowledge of household members, while their knowledge of cases at school or in other social situations would be incomplete, especially early in the pandemic period when testing was not widely available. The combination of these limitations would result in a falsely elevated higher relative risk for those exposed to household members than for those exposed to work/social contacts. A second limitation is the possibility of recall bias as we asked that participants recall information about exposure to people with COVID-19 up to 15 months before their enrolment in the study.

\section{Conclusion}

These interim results found that education workers were at similar risk of infection as other Canadian adults during the first 18 months of the pandemic and that about $40 \%$ of infections were attributable to exposure to household members, family, or friends while $35 \%$ were associated with unknown exposure(s) and $24 \%$ were associated with exposure to other educational staff and/or students. We could not detect any difference in the risk of infection by the degree of exposure to children as opposed to other workers, or in schools for children of different ages. In the coming months, there is the potential for increased risks to education workers due to the emergence of the delta and omicron variants with higher transmissibility, the return to in-person schooling in Ontario, and an increased rate of infection in unvaccinated children as public health restrictions are lifted. Potential reductions in risk may result from protection from vaccines and from the implementation of transmission reduction measures in school buildings. Despite high vaccination rates, careful attention to protective practices like mask-wearing, physical distancing, hand hygiene, and cohorting is still needed in schools and other workplaces over the next months of the pandemic.

\section{Contributions to knowledge}

What does this study add to existing knowledge?

- People working in the education sector were equally likely to be infected with SARS-CoV-2 as other adults in Ontario.

- Although transmission did occur in the workplace, education workers were more likely to be infected by someone living in their household.

What are the key implications for public health interventions, practice or policy?

- Exposure to anyone, including household members, who have COVID-19 or have recently been exposed to someone else with COVID-19 is a risk for infection.

- Exposure to others while travelling remains a risk for infection with SARS-CoV-2.

Author contributions All the authors contributed to the study conception and design. Material preparation, data collection, and analysis were performed by Brenda Coleman. The first draft of the manuscript was written by Brenda Coleman and all the authors commented on previous versions of the manuscript. All the authors read and approved the final manuscript. 
Funding This study was funded by the Government of Canada through the COVID-19 Immunity Task Force (grant number 2021-HQ-000149).

Data availability Data are available through the COVID-19 Immunity Task Force.

Code availability Not applicable

\section{Declarations}

Ethics approval Ethics approval was granted by Sinai Health System Research Ethics Board and conducted in accordance with standards established in the declaration of Helsinki.

Consent to participate Consent to participate was given prior to collection of any data from all individual participants included in the study.

Consent for publication No individual's data or image is published.

Conflict of interest The authors declare no competing interests.

\section{References}

Andridge, R. R., \& Little, R. J. (2010). A review of hot deck imputation for survey non-response. Int Stat Rev, 78(1), 40-64. https://doi.org/ 10.1111/j.1751-5823.2010.00103.x

Bi, Q., Lessler, J., Eckerle, I., Lauer, S. A., Kaiser, L., Vuilleumier, N., et al. (2021). Insights into household transmission of SARS-CoV-2 from a population-based serological survey. Nat Commun, 12(1), 3643. https://doi.org/10.1038/s41467-021-23733-5

Canadian Blood Services. (2021). Poorer neighbourhoods and racialized communities continue to lag behind in vaccine coverage: Latest Canadian Blood Services results. Retrieved from https://www. covid19immunitytaskforce.ca/poorer-neighbourhoods-andracialized-communities-continue-to-lag-behind-in-vaccinecoverage-latest-canadian-blood-services-results/

Ehrhardt, J., Ekinci, A., Krehl, H., Meincke, M., Finci, I., Klein, J., et al. (2020). Transmission of SARS-CoV-2 in children aged 0 to 19 years in childcare facilities and schools after their reopening in May 2020, Baden-Württemberg, Germany. Euro Surveill, 25(36), 2001587. https://doi.org/10.2807/1560-7917.Es.2020.25.36.2001587

Gallagher-Mackay, K., Srivastava, P., Underwood, K., Dhuey, E., McCready, L., Born, K., ... Ontario COVID-19 Science Advisory Table. (2021). COVID-19 and education disruption in Ontario: Emerging evidence on impacts. Science Briefs of the Ontario COVID-19 Science Advisory Table, (1.1). https://doi.org/10.47326/ ocsat.2021.02.34.1.0

Gandini, S., Rainisio, M., Iannuzzo, M. L., Bellerba, F., Cecconi, F., \& Scorrano, L. (2021). A cross-sectional and prospective cohort study of the role of schools in the SARS-CoV-2 second wave in Italy. Lancet Reg Health Eur, 5, 100092. https://doi.org/10.1016/j. lanepe.2021.100092

Government of Canada. (2018). Tri-council policy statement: Ethical conduct for research involving humans. Retrieved from https:// ethics.gc.ca/eng/policy-politique_tcps2-eptc2_2018.html

Government of Canada. (2019). Guidance Document: Part C, Division 5 of the Food and Drug Regulations "Drugs for Clinical Trials Involving Human Subjects" (GUI-0100) - Summary. Retrieved from https://www.canada.ca/en/health-canada/services/drugshealth-products/compliance-enforcement/good-clinical-practices/ guidance-documents/guidance-drugs-clinical-trials-humansubjects-gui-0100.html

Government of Ontario. (2020a, 2021-Aug-21). Guide to reopening Ontario's schools. Retrieved from https://www.ontario.ca/page/ guide-reopening-ontarios-schools

Government of Ontario. (2020b). News release: Ontario takes additional steps to better protect students and staff [Press release]. Retrieved from https://news.ontario.ca/en/release/57990/ontario-takesadditional-steps-to-better-protect-students-and-staff

Government of Ontario. (2021). Statement: Safety of schools remains priority number one for Ontario [Press release]. Retrieved from https://news.ontario.ca/en/statement/60085/safety-of-schoolsremains-priority-number-one-for-ontario

Gudbjartsson, D. F., Helgason, A., Jonsson, H., Magnusson, O. T., Melsted, P., Norddahl, G. L., et al. (2020). Spread of SARS-CoV2 in the Icelandic population. New England Journal of Medicine, 382(24), 2302-2315. https://doi.org/10.1056/NEJMoa2006100

Hu, M., Lin, H., Wang, J., Xu, C., Tatem, A. J., Meng, B., et al. (2021). Risk of coronavirus disease 2019 transmission in train passengers: An epidemiological and modeling study. Clinical Infectious Diseases, 72(4), 604-610. https://doi.org/10.1093/cid/ciaa1057

ICES. (2021). ICES COVID-19 dashboard, applied health research questions. Retrieved from: https://www.ices.on.ca/DAS/AHRQ/ COVID-19-Dashboard\#downloads

Irfan, O., Li, J., Tang, K., Wang, Z., \& Bhutta, Z. A. (2021). Risk of infection and transmission of SARS-CoV-2 among children and adolescents in households, communities and educational settings: A systematic review and meta-analysis. $J$ Glob Health, 11, 05013. https://doi.org/10.7189/jogh.11.05013

Lash, R. R., Moonan, P. K., Byers, B. L., Bonacci, R. A., Bonner, K. E., Donahue, M., et al. (2021). COVID-19 case investigation and contact tracing in the US, 2020. JAMA Network Open, 4(6), e2115850. https://doi.org/10.1001/jamanetworkopen.2021.15850

Li, F., Li, Y. Y., Liu, M. J., Fang, L. Q., Dean, N. E., Wong, G. W. K., et al. (2021). Household transmission of SARS-CoV-2 and risk factors for susceptibility and infectivity in Wuhan: A retrospective observational study. Lancet Infect Dis, 21(5), 617-628. https://doi. org/10.1016/s1473-3099(20)30981-6

Li, W., Zhang, B., Lu, J., Liu, S., Chang, Z., Peng, C., et al. (2020). Characteristics of household transmission of COVID-19. Clinical Infectious Diseases, 71(8), 1943-1946. https://doi.org/10.1093/cid/ ciaa450

Liu, T., Liang, W., Zhong, H., He, J., Chen, Z., He, G., et al. (2020). Risk factors associated with COVID-19 infection: A retrospective cohort study based on contacts tracing. Emerg Microbes Infect, 9(1), 15461553. https://doi.org/10.1080/22221751.2020.1787799

Macartney, K., Quinn, H. E., Pillsbury, A. J., Koirala, A., Deng, L., Winkler, N., et al. (2020). Transmission of SARS-CoV-2 in Australian educational settings: A prospective cohort study. The Lancet Child \& Adolescent Health.https://doi.org/10.1016/S23524642(20)30251-0

Madewell, Z. J., Yang, Y., Longini Jr., I. M., Halloran, M. E., \& Dean, N. E. (2020). Household transmission of SARS-CoV-2: A systematic review and meta-analysis. JAMA Network Open, 3(12), e2031756. https://doi.org/10.1001/jamanetworkopen.2020.31756

Meuris, C., Kremer, C., Geerinck, A., Locquet, M., Bruyère, O., Defêche, J., et al. (2021). Transmission of SARS-CoV-2 after COVID-19 screening and mitigation measures for primary school children attending school in Liège, Belgium. JAMA Netw Open, 4(10), e2128757. https://doi.org/10.1001/jamanetworkopen.2021.28757

Ng, O. T., Marimuthu, K., Koh, V., Pang, J., Linn, K. Z., Sun, J., et al. (2021). SARS-CoV-2 seroprevalence and transmission risk factors among high-risk close contacts: A retrospective cohort study. The Lancet. Infectious diseases, 21(3), 333-343. https://doi.org/10. 1016/S1473-3099(20)30833-1 
Ontario College of Teachers. (2020). 2020 annual report. Retrieved from https://reports.oct.ca/en/2020/Statistics/Membership-Demographics

Ontario Ministry of Education. (2019). Quick facts: Ontario schools 2016-17. Retrieved from http://www.edu.gov.on.ca/eng/general/ elemsec/quickfacts/2016_2017.html

Ontario Ministry of Education. (2021). Education facts, 2019-2020. Retrieved from http://www.edu.gov.on.ca/eng/educationfacts.html

Ontario Ministry of Health. (2021). Ontario's COVID-19 vaccination plan. Retrieved from https://covid-19.ontario.ca/ontarios-covid-19vaccination-plan\#our-three-phased-vaccination-plan

Ortiz, N., Villarino, E., Lee, J., Bajema, K., Ricaldi, J., Smith, S., et al. (2021). Epidemiologic findings from case investigations and contact tracing for first 200 cases of coronavirus disease, Santa Clara county, California, USA. Emerging Infectious Disease journal, 27(5), 1301. https://doi.org/10.3201/eid2705.204876

Public Health Ontario. (2021). Ontario COVID-19 data tool. Retrieved from: https://www.publichealthontario.ca/en/data-and-analysis/ infectious-disease/covid-19-data-surveillance/covid-19-data-tool? tab=summary

StatCorp LLC. (2021). Stata/SE (Version 16.1). College Station, TX.
Turner Consulting Group. (2015). Voices of Ontario black educators, an experiental report. Retrieved from https://youthrex.com/report/ voices-of-ontario-black-educators-an-experiential-report/

Ulyte, A., Radtke, T., Abela, I. A., Haile, S. R., Blankenberger, J., Jung, R., et al. (2021). Variation in SARS-CoV-2 seroprevalence across districts, schools and classes: Baseline measurements from a cohort of primary and secondary school children in Switzerland. BMJ Open, 11(7), e047483. https://doi.org/10.1136/bmjopen-2020047483

Varma, J. K., Thamkittikasem, J., Whittemore, K., Alexander, M., Stephens, D. H., Arslanian, K., et al. (2021). COVID-19 infections among students and staff in New York city public schools. Pediatrics, 147(5), e2021050605. https://doi.org/10.1542/peds. 2021-050605

York Region tutoring. (2018). Private schools: List of private schools in Ontario. Retrieved from https://yorkregiontutoring.com/privateschools/list-of-private-schools-in-ontario/

Publisher's note Springer Nature remains neutral with regard to jurisdictional claims in published maps and institutional affiliations. 